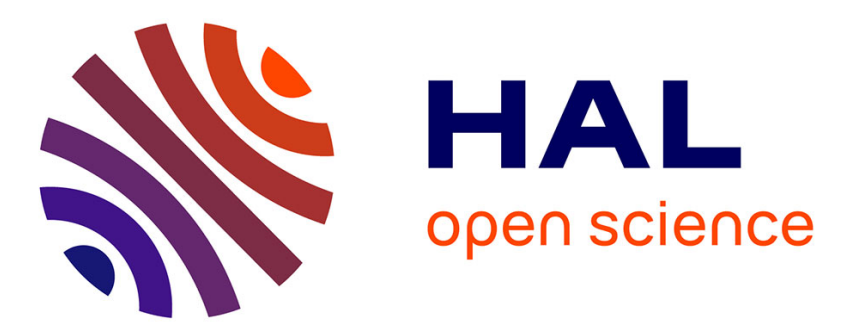

\title{
Modelling urban noise exposure and contribution of noise reflection against façades of buildings: Does correction matter?
}

Quentin Tenailleau, Bernard Nadine, Sophie Pujol, Daniel Joly, Frédéric Mauny, Hélène Houot

\section{To cite this version:}

Quentin Tenailleau, Bernard Nadine, Sophie Pujol, Daniel Joly, Frédéric Mauny, et al.. Modelling urban noise exposure and contribution of noise reflection against façades of buildings: Does correction matter?. ICA 2013 Montreal, Jun 2013, Montreal, Canada. pp.1-4, 10.1121/1.4799998 . hal-00850202

\section{HAL Id: hal-00850202 https://hal.science/hal-00850202}

Submitted on 5 Aug 2013

HAL is a multi-disciplinary open access archive for the deposit and dissemination of scientific research documents, whether they are published or not. The documents may come from teaching and research institutions in France or abroad, or from public or private research centers.
L'archive ouverte pluridisciplinaire HAL, est destinée au dépôt et à la diffusion de documents scientifiques de niveau recherche, publiés ou non, émanant des établissements d'enseignement et de recherche français ou étrangers, des laboratoires publics ou privés. 


\title{
Proceedings of Meetings on Acoustics
}


\author{
ICA 2013 Montreal \\ Montreal, Canada
}

2 - 7 June 2013

Noise

Session 5aNSa: Urban Noise and Modeling

\section{5aNSa3. Modeling urban noise exposure and contribution of noise reflection against façades of buildings: Does correction matter?}

Quentin M. Tenailleau*, Nadine Bernard, Sophie Pujol, Daniel Joly, Hélène Houot and Frédéric Mauny

*Corresponding author's address: UMR 6249 "chrono-environnement", Université de Franche-Comté, CMC - Hopital St Jacques, Besançon, 25000, France, France, quentin.tenailleau@univ-fcomte.fr

European noise directives advise to apply corrections when measuring and modelling noise levels close to a building in the aim of excluding the contribution of noise reflection against the façade. The advised $-3 \mathrm{~dB}$ correction is still subject to discussion. In order to investigate the needed correction for a household exposure studies, a high definition noise model was used to estimate noise levels at 10,394 inhabitable buildings. Three buffers were used to sample area surrounding façades of buildings. The surfaces were defined between the following distances: i) 0 and 2m, ii) 0 and $6 \mathrm{~m}$, iii) 2 and $6 \mathrm{~m}$. No differences between the distribution structures were observed. Mean noise levels do not differ significantly between the buffers methods (respectively i) $49.6 \pm 6.7 \mathrm{~dB}$, ii) $49.7 \pm 6.7 \mathrm{~dB}$, iii) $49.8 \pm 6.7 \mathrm{~dB}$; $\mathrm{p}<0.01$ ). Same observation can be made for maximum noise levels (respectively i) $52.0 \pm 7.2 \mathrm{~dB}$, ii) $52.5 \pm 7.2 \mathrm{~dB}$, iii) $52.4 \pm 7.2 \mathrm{~dB}$; $<<0.01$ ). These results show no or light differences between indices computed by the three sampling methods. They are in favour of no or at least a low correction value to deal with the contribution of noise reflection against the façade of a building.

Published by the Acoustical Society of America through the American Institute of Physics 


\section{INTRODUCTION}

Sampling at the most exposed façade is advised by European Union Noise Directive (END) as a standardized method to assess environmental noise exposure to a building's inhabitants (European Commission, 2002). Due to reflection against the building's walls, END also advises a $-3 \mathrm{~dB}$ correction to be applied to noise exposure assessed using this technique (International Standards Organization, 2000). Exclusion of reflected sound contribution keeps only incident environmental sound. Nowadays, studies are mainly based on exposure models (Babisch et al., 2005; de Kluizenaar et al., 2007; Murphy et al., 2009; Selander et al., 2009), and it is unknown whether corrections are needed when using modeled noise levels in exposure assessment. Moreover, authors don't always use the facade which is the most exposed (Beelen et al., 2009; Bodin et al., 2009; Pujol et al., 2012a), depending on the legislation in their country or the purpose of their research. Few studies exist based on the impact of the sampled facade on the noise exposure (Licitra et al., 2010). The objectives of this paper are to investigate the need for the $-3 \mathrm{~dB}$ advised correction with noise models, and to quantify the impact of the chosen facade on assessed noise exposure. Concerning the recommended correction, our hypothese is that, if it is needed due to sound reflection, then noise levels computed on the first two meters from the building's wall should be superior to those computed on a higher distance.

\section{MATERIALS \& METHODS}

\section{Noise Modelling}

Daily equivalent continuous A weighted sound level $\left(\mathrm{L}_{\text {Aeq24H }}\right)$ was calculated in the French medium-sized city of Besançon, using the noise model computed in accordance with the END by Pujol et al. (Pujol et al., 2012b; Pujol et al., 2010). Topographic, road and building data from the French National Geographical Institute database (Bdtopo2006), and meteorological data from the French National Meteorological Service were integrated in the noise modeling software MITHRA-SIGC (V2), developed by a company called Geomod and the French scientific and technical center for building (CSTB). Four sources of noise were included: road traffic, railway traffic, pedestrian traffic and water fountains. The model was validated using a noise measurement campaign conducted in front of 44 dwellings (Pujol et al., 2012a). In order to study multi-exposure to noise and air pollutants, a noise map displaying noise exposure at 2 meters above ground, has been built from this model. This noise map has been introduced as a $4 \mathrm{~m}^{2}(2 \mathrm{~m} \times 2 \mathrm{~m})$ raster grid in ESRI arcGIS (V9.3.1) software with each pixel giving a noise level rounded to the nearest decibel unit. A mask based on the building layer has been created to avoid sampling on the site of a building. The 10,394 residential buildings, located at least $400 \mathrm{~m}$ inside the city border to limit the boundary effect, have been chosen as a basis for noise exposure assessment.

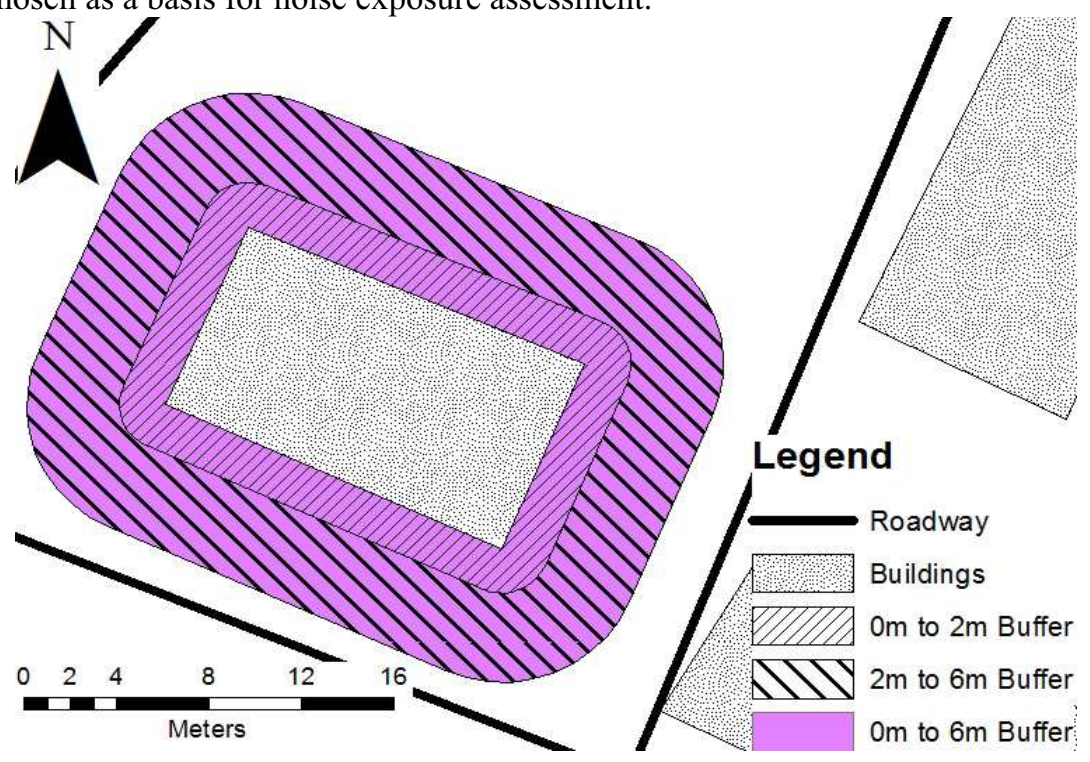

FIGURE 1. Example of the three buffer sampling methods 


\section{Distance-to-Wall Sampling}

Three buffers surrounding the facade have been defined for each building, with the following distance from the building's wall: $0 \mathrm{~m}$ to $2 \mathrm{~m}, 0 \mathrm{~m}$ to $6 \mathrm{~m}$ and $2 \mathrm{~m}$ to $6 \mathrm{~m}$ (Figure 1). The " $0 \mathrm{~m}$ to $2 \mathrm{~m}$ " buffer is composed of the first ring of pixels in contact with the building's façade. The " $0 \mathrm{~m}$ to $6 \mathrm{~m}$ " buffer samples noise exposure on a larger surface while the " $2 \mathrm{~m}$ to $6 \mathrm{~m}$ " buffer corresponds to the same surface minus the first ring of pixels.

\section{Façade Approach}

For each distance-to-wall buffer, the average and the maximum noise levels have been calculated and assigned to the corresponding building. Average noise levels are computed from noise levels obtained for each pixel under the buffers while maximum noise levels are computed from the single pixel giving the maximum noise level. These average and maximum values are respectively the basis for our two facade approaches: the "Facade average" and the "Most exposed facade".

\section{Statistical Analysis}

A first analysis was conducted to test for equivalence between the different buffers. A two-one sided t-test (TOST) for paired series was used (Berger and Hsu, 1996). Three TOST were performed: $0 \mathrm{~m}$ to $2 \mathrm{~m}$ vs $2 \mathrm{~m}$ to $6 \mathrm{~m}$, $0 \mathrm{~m}$ to $2 \mathrm{~m}$ vs $0 \mathrm{~m}$ to $6 \mathrm{~m}$ and $2 \mathrm{~m}$ to $6 \mathrm{~m}$ vs $0 \mathrm{~m}$ to $6 \mathrm{~m}$. According to this multiple test design, the Bonferroni adjustment to the Type I error probabilities was applied. Equivalence $99 \%$ confidence intervals were also calculated and compared to the equivalence zone of $[-1 \mathrm{~dB} ;+1 \mathrm{~dB}]$. Secondly, façade approaches were compared using Wilcoxon signed-rank test. All tests were performed using R statistics 2.13.1. The level of significance was set at 0.05 .

\section{RESULTS}

Mean computed noise levels are of $50 \mathrm{~dB}$ with a range value of $46 \mathrm{~dB}$ for all three distance-to-wall buffers of the "facade average" approach. For the "Most exposed facade", mean noise levels are of $52 \mathrm{~dB}$ with a range value of 48 $\mathrm{dB}$ (Table).

\section{Distance to Wall Sampling}

The three distance-to-wall buffers sampling means are equivalent for the "Facade average" approach (Figure 2, and Table). All 99\% confidence intervals are between $-1 \mathrm{~dB}$ and $1 \mathrm{~dB}$ (Figure 3). Comparison between buffers indicates few variations in the affected noise levels: $95 \%$ of the buildings show a difference lower than $1 \mathrm{~dB}$ for " $0 \mathrm{~m}$ to $6 \mathrm{~m}$ "-“ $0 \mathrm{~m}$ to $2 \mathrm{~m}$ ", lower than $1.4 \mathrm{~dB}$ for " $2 \mathrm{~m}$ to $6 \mathrm{~m}$ "-“" $0 \mathrm{~m}$ to $2 \mathrm{~m}$ ", and lower than $0.8 \mathrm{~dB}$ for " $0 \mathrm{~m}$ to $6 \mathrm{~m}$ "-“ $2 \mathrm{~m}$ to $6 \mathrm{~m} "$.

Similar results are obtained with the "Most exposed façade" approach (Figure 2, Figure 3 and Table). Considering the " $0 \mathrm{~m}$ to $6 \mathrm{~m}$ "-" $0 \mathrm{~m}$ to $2 \mathrm{~m}$ " and the " $2 \mathrm{~m}$ to $6 \mathrm{~m}$ "- " $0 \mathrm{~m}$ to $2 \mathrm{~m}$ " comparisons, $95 \%$ of the buildings show a difference lower than $2 \mathrm{~dB}$ while this difference is lower than $1 \mathrm{~dB}$ for " $0 \mathrm{~m}$ to $6 \mathrm{~m}$ "- $2 \mathrm{~m}$ to $6 \mathrm{~m}$ ".

TABLE. Noise levels $(\mathrm{dB})$ computed on the surface of all three buffers, grouped by facade approach. $\mathrm{SD}=\mathrm{Standard}$ deviation

\begin{tabular}{lccccccccc}
\hline & & & Façade ave rage & \multicolumn{3}{c}{ Most exposed façade } & \multicolumn{3}{c}{ Façade average - Most exposed façade } \\
& $\mathbf{0 m}$ to $\mathbf{2 m}$ & $\mathbf{0}$ to $\mathbf{6 m}$ & $\mathbf{2 m}$ to $\mathbf{6 m}$ & $\mathbf{0 m}$ to $\mathbf{2 m}$ & $\mathbf{0 m}$ to $\mathbf{m}$ & $\mathbf{2 m}$ to $\mathbf{6 m}$ & $\mathbf{0 m}$ to $\mathbf{2 m}$ & $\mathbf{0 m}$ to $\mathbf{m}$ & $\mathbf{2 m}$ to $\mathbf{6 m}$ \\
\hline Mean (SD) & $49.6(6.7)$ & $49.7(6.7)$ & $49.8(6.7)$ & $52.0(7.2)$ & $52.5(7.2)$ & $52.4(7.2)$ & $2.3(1.4)$ & $2.7(1.5)$ & $2.5(1.4)$ \\
Min - Max & $25-71$ & $25-71$ & $25-71$ & $26-74$ & $26-74$ & $26-74$ & $0-16$ & $0-20$ & $0-14$ \\
$1^{\text {st }}$ Quartile & 45 & 45 & 45 & 47 & 48 & 48 & 1 & 2 & 2 \\
Median $^{\text {rd }}$ & 49 & 49 & 50 & 52 & 52 & 52 & 2 & 2 & 2 \\
$3^{\text {Q }}$ Quartile & 54 & 54 & 54 & 56 & 57 & 57 & 3 & 3 & 3 \\
\hline
\end{tabular}






FIGURE 2. Boxplots of the noise levels structure evaluated for each sampling methods and each façade approach ( $\mathrm{n}=10394)$

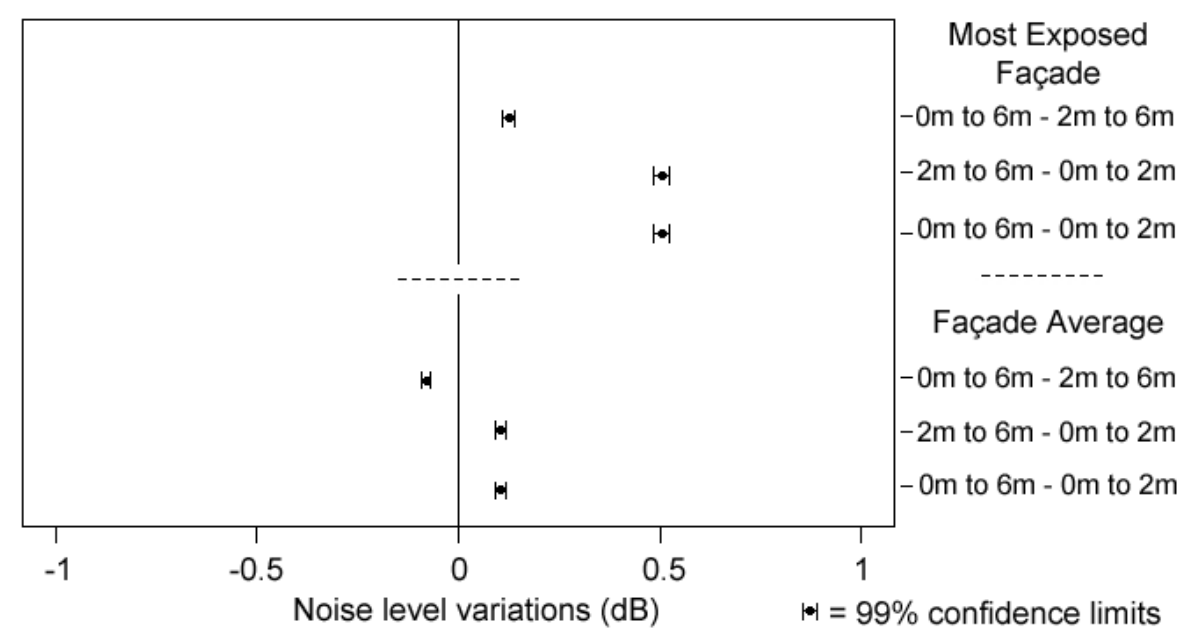

FIGURE 3. Plots of the $99 \%$ confidence interval for the noise levels differences between buffers ( $\mathrm{n}=10394$ ).

\section{Facade Approach}

Noise values obtained using the "Most exposed façade" are significantly higher than those obtained with the "Facade average", whatever the buffer size : on average $+2.5 \mathrm{~dB}(\mathrm{p}<0.01$, Figure 2 and Table). For $95 \%$ of the buildings, the differences between the two facade approaches are less than $+6 \mathrm{~dB}$ for all buffers (Figure 4 ). 

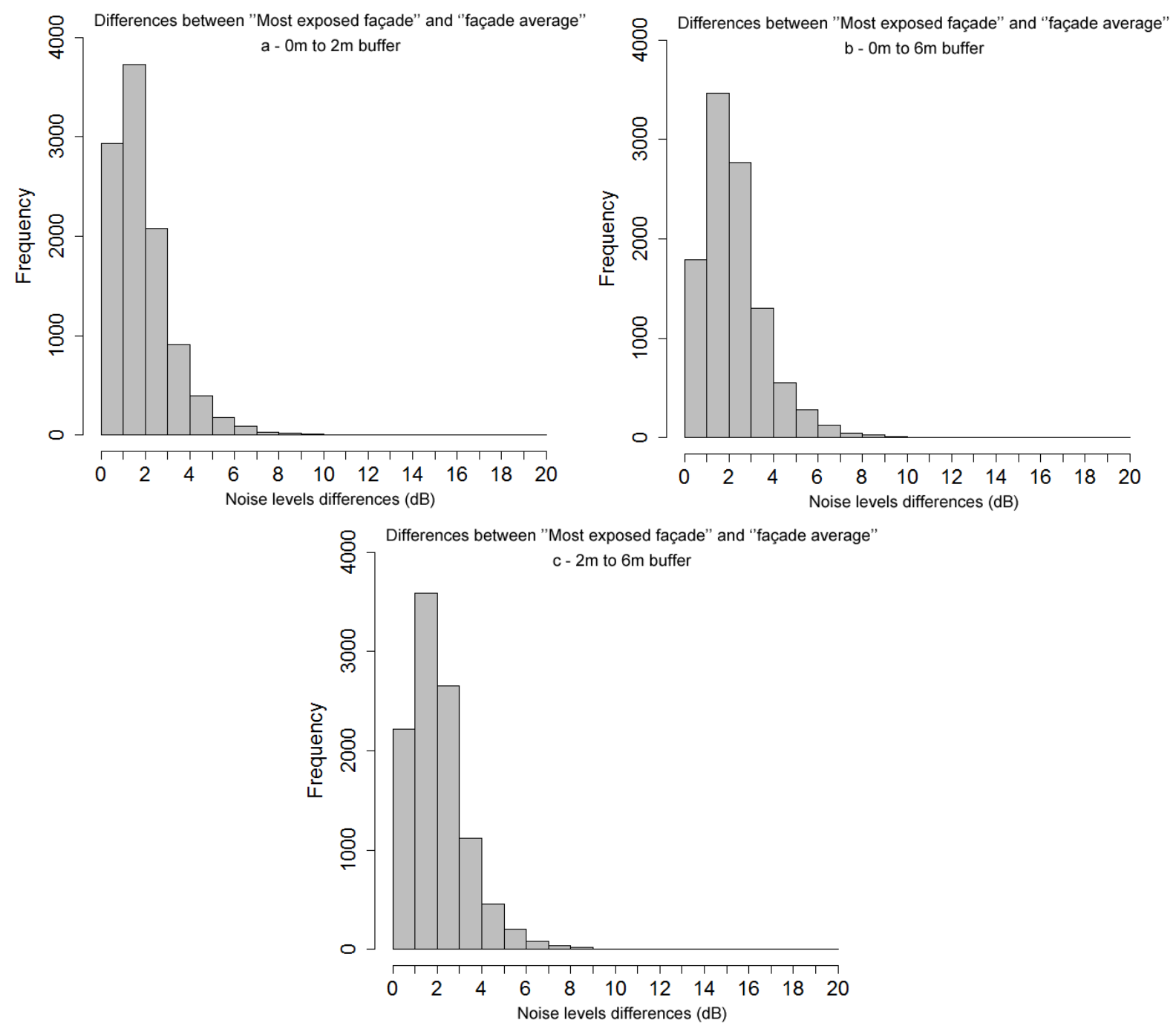

FIGURE 4. a, b \& c: Distributions of the noise levels differences between the façade approaches, for each buffers ( $\mathrm{n}=10394)$.

\section{DISCUSSION}

The results of this study indicate no difference between noise levels obtained from the three distance-to-wall buffers sampling, both for the "Facade average" approach and for the "Most exposed façade" approach. Noise levels observed using the "Most exposed façade" are significantly higher than those obtained using the "Facade average" approach. These results were obtained from a noise model computed in accordance with European Noise Directives and official guidelines (CERTU, 2006; European Commission, 2002; WG-AEN, 2006). To match French pollution map creation rules, noise levels were calculated at 2 meters above ground instead of the $4 \mathrm{~m}$ advised by END for strategic noise maps (European Commission, 2002). This difference constitutes a limit to the study, as the noise map cannot fully be considered as a strategic noise map.

To our knowledge, while the need for correction during field sampling has already been proved (Memoli et al., 2008), this study is the first to investigate the need for correction when using a noise model to assess exposure at a building facade. END and the International Standards Organization recommend two corrections when field measuring at the facade of a building: a $-6 \mathrm{~dB}$ correction is to be applied when the measurement is made directly at the surface of the wall (International Standards Organization, 2006), and a $-3 \mathrm{~dB}$ when sampling is at $2 \pm 0.5 \mathrm{~m}$ from the façade (International Standards Organization, 2000). Considering these recommendations, the $0 \mathrm{~m}$ to $2 \mathrm{~m}$ buffer appears to be the best area to investigate the need for correction as noise level should be significantly higher, from $+6 \mathrm{~dB}$ to $+3 \mathrm{~dB}$. The results show that this area and a larger zone, where wall-reflected sound could be considered as negligible, are equivalent. END recommendations are however made for punctual measurements while methods 
used in this study are surface based. Consequently, correcting for wall reflection does not seem to be needed when using a $2 \mathrm{~m}$ grid model to assess noise exposure, but should be considered when field measuring at one point of a building's facade.

Differences between the facade average and the most exposed facade have already been observed (Licitra et al., 2010) with similar values. The END recommendation of using the most exposed facade has been made to maximize exposure assessed at the population scale and take the cautious approach in the interest of risk management. The use of the most exposed facade as a reference for household exposure studies can lead to misclassification of human exposure. A better alternative, when such information is available, appears to be the use of the subject dwelling's facade as a basis for noise exposure assessment.

\section{CONCLUSION}

For both approaches, the similarity of the noise levels obtained regardless of the distance to the facade seems to be in favour of no correction when using a noise model to assess noise exposure at a building facade. The choice of the facade used for exposure assessment alters the resulting noise level and selection should be made carefully in accordance with the aim of the study.

\section{ACKNOWLEDGMENTS}

Quentin Tenailleau is a Ph.D. student supported by a grant from the city of Besançon. The authors would like to thanks the city services, the urban community of Besançon (CAGB), the Besançon Urban Developpement Agency (AUDAB) and the Departemental Public Works Directorate (DDE), for their technical support.

\section{REFERENCES}

Babisch, W., Beule, B., Schust, M., Kersten, N., and Ising, H. (2005). "Traffic noise and risk of myocardial infarction," Epidemiology 16, 33-40.

Beelen, R., Hoek, G., Houthuijs, D., van den Brandt, P. A., Goldbohm, R. A., Fischer, P., Schouten, L. J., Armstrong, B., and Brunekreef, B. (2009). "The joint association of air pollution and noise from road traffic with cardiovascular mortality in a cohort study," Occup Environ Med 66, 243-250.

Berger, R. L., and Hsu, J. C. (1996). "Bioequivalence Trials, Intersection-Union Tests and Equivalence Confidence Sets," Statistical Science 11, 283-319.

Bodin, T., Albin, M., Ardö, J., Stroh, E., Ostergren, P., and Björk, J. (2009). "Road traffic noise and hypertension: results from a cross-sectional public health survey in southern Sweden," Environ Health 8, 38.

CERTU (2006). "Comment réaliser les cartes de bruit stratégiques en agglomération," , 122.

de Kluizenaar, Y., Gansevoort, R. T., Miedema, H. M. E., and de Jong, P. E. (2007). "Hypertension and road traffic noise exposure," J Occup Environ Med 49, 484-492.

European Commission (2002). "Directive 2002/49/EC of the European Parliament and of

the Council of 25 June 2002 relating to the assessment and management of environmental noise.," Official Journal of the European Communities 189, 12-25.

International Standards Organization (2000). "Acoustics - Measurements of sound insulation in buildings and of building elements - Part 5: Field measurements of airborne sound insulation of façade elements and façades," ISO 140-5,.

International Standards Organization (2006). "Acoustics - Description, assessment and measurement of environmental noise Part 2: Determination of environmental noise levels," ISO/FDIS 1996-2,.

Licitra, G., Ascari, E., and Brambilla, G. (2010). "Comparative analysis of methods to evaluate noise exposure and annoyance of people," in proceedings of the 20th International Congress on Acoustics, ICA 2010, 5.

Memoli, G., Paviotti, M., Kephalopoulos, S., and Licitra, G. (2008). "Testing the acoustical corrections for reflections on a fac, ade," Applied Acoustics 69, 479-495.

Murphy, E., King, E., and Rice, H. (2009). "Estimating human exposure to transport noise in central Dublin, Ireland," Environ Int 35, 298-302.

Pujol, S., Berthillier, M., Defrance, J., Lardiès, J., Petit, R., Houot, H., Levain, J., Masselot, C., and Mauny, F. (2012a). "Urban ambient outdoor and indoor noise exposure at home: A population-based study on schoolchildren," Applied Acoustics 73, 741750.

Pujol, S., Houot, H., Antoni, J., and Mauny, F. (2012b). "Linking traffic and noise models to explore spatio-temporal distribution of noise pollution: an example in Besançon (France)," in proceedings of the 19th International Congress on Sound and Vibration, Vilnuis (Lithuania),

Pujol, S., Houot, H., Berthillier, M., Defrance, J., Lardies, J., Bongain, S., Levain, J., Masselot, C., Petit, R., and Mauny, F.

(2010). "Modélisation de l'exposition au bruit en milieu urbain et études épidémiologiques: quelles sources sonores ?," in 
proceedings of the Neuvièmes Rencontres de Théo Quant, Besançon (France), 10pp.

Selander, J., Nilsson, M. E., Bluhm, G., Rosenlund, M., Lindqvist, M., Nise, G., and Pershagen, G. (2009). "Long-term exposure to road traffic noise and myocardial infarction," Epidemiology 20, 272-279.

WG-AEN (2006). "Good Practice Guide for Strategic Noise Mapping and the Production of Associated Data on Noise

Exposure,", 129. 